\title{
EFEITO DA UMIDADE DO SOLO NA BIOLOGIA DE Rhopalosiphum maidis (FITCH, 1856) (HEMIPTERA: APHIDIDAE) EM MILHO
}

\author{
WILSON J.M.S. MAIA ${ }^{1}$, JÚLIO N. C. LOUZADA²; IVAN CRUZ³; CARVALHO C. ECOLE; \\ TEREZINHA J.A.F. MAIA ${ }^{1}$
}

\begin{abstract}
${ }^{1}$ UFRA, Instituto de Ciências Agrárias, C.P. 917, 66.077-530, Belém, PA, wilson.maia@ufra.edu.br
${ }^{2}$ UFLA, Departamento de Biologia, Caixa postal 37, Campus Universitário, 37.200-000, Lavras, MG, juliolouzada@ufla.br ${ }^{3}$ Embrapa Milho e Sorgo, Rod. MG 424, km 65, CP 151, 35701-970, Sete Lagoas, MG, ivancruz@ cnpms.embrapa.br(Autor para correspondência)

${ }^{4}$ UFLA, Departamento de Entomologia, Caixa postal 37,37.200-000, Campus Universitário, Lavras, MG, ccecole@ufla.br
\end{abstract}

Revista Brasileira de Milho e Sorgo, v.5, n.1, p.37-47, 2006

\begin{abstract}
RESUMO - O efeito da umidade do solo na biologia de Rhopalosiphum maidis (Fitch) em plantas de milho (Zea mays) foi avaliado em casa de vegetação. Foi utilizado o delineamento experimental inteiramente casualizado, com três tratamentos $(20 \%, 40 \%$ e $100 \%$ de dotação hídrica) e quatro repetições, sendo cada parcela experimental constituída por um vaso de polietileno de cinco litros contendo duas plantas de milho no estádio fenológico três e com dez pulgões adultos confinados em microgaiolas de $10 \mathrm{~mm}$ de altura por $10 \mathrm{~mm}$ de diâmetro (cinco pulgões/microgaiola/planta), perfazendo um total de 40 pulgões/tratamento. As variáveis biológicas do pulgão estudadas foram: a duração de cada instar, dos períodos pré-reprodutivo, pós-reprodutivo e reprodutivo, a produção diária, total de ninfas e de alados e o ciclo de vida de $R$. maidis. Houve efeito da umidade do solo onde estavam as plantas de milho, tanto na duração do desenvolvimento dos pulgões, em cada um dos quatro ínstares, quanto na duração da fase ninfal, sendo que os pulgões que se desenvolveram em plantas de milho com défice de água de $80 \%$ completaram os estádios ninfais num menor período. De igual forma, o período reprodutivo e a longevidade dos adultos foram mais curtos nos pulgões que se desenvolveram em plantas de milho em solo com $20 \%$ da capacidade de campo. Porém, não houve efeito dos tratamentos na duração do período pós-reprodutivo. Por outro lado, adultos de pulgões que se desenvolveram nas plantas em solo com $20 \%$ da água necessária produziram a primeira ninfa num menor período do que os desenvolvidos nas plantas que receberam $40 \%$ de água na capacidade de campo. Pulgões cuja fase jovem ocorreu em plantas de milho sob estresse hídrico de $80 \%$ desapareceram mais rapidamente do que aqueles desenvolvidos em plantas sob regime de estresse hídrico de $60 \%$. Esses resultados indicam que o manejo da água no milho pode ser uma estratégia no controle de fatores naturais que afetam tanto a população como o número de gerações do pulgão no ambiente, podendo reduzir a necessidade do controle químico.
\end{abstract}

Palavras-chave: Insecta, Zea mays, pulgão-do-milho, resistência induzida, ecologia, manejo de pragas.

\section{EFFECT OF SOIL MOISTURE ON THE BIOLOGY OF Rhopalosiphum maidis (FITCH, 1856) (HEMIPTERA: APHIDIDAE) ON MAIZE}

\footnotetext{
ABSTRACT - The effect of soil moisture on the biology of Rhopalosiphum maidis (Fitch) fed on maize plants (Zea mays L.) was evaluated under greenhouse conditions. A
} 
completely randomized experimental design with three treatments $(20 \%, 40 \%$ and $100 \%$ water availability) and four replications was used. Each experimental plot was a 5 liter plastic pot containing two corn plants at the third developmental plant stage and 10 adult aphids confined into micro-cages $(10 \mathrm{~mm}$ high x $10 \mathrm{~mm}$ diameter) (five aphids/microcage/plant) and total of 40 aphids per treatment. The biological variables of the aphids recorded were: duration of each instar, duration of the pre-reproductive, post-reproductive and reproductive periods; daily production of nymphs and winged adults, and life-cycle of $R$. maidis. The amount of water supply to the corn plants affected the duration of the developmental time of the nymphs, in each one of the four instars, as well as on duration of the total nymph phase. The aphids that developed on corn plants with $80 \%$ of water deficit completed the nymph instars in shorter period of time. Similarly, the reproductive period and longevity of adults were shorter for aphids that developed on plants under $20 \%$ of the field capacity. There was no effect of treatments, however, on duration of the post-reproductive period. Adult aphids on plants with $80 \%$ water deficit (only $20 \%$ of the needed water) produced the first nymph in shorter period of time than those on plants that received $40 \%$ of water to reach field capacity. Aphids whose nymphs developed on corn plants under $80 \%$ water deficit disappeared more rapidly from the plants than those developed on plants under a $60 \%$ water deficit. These results indicate that the water management on maize field might be an important strategy to control the population as well as the number of generations of $R$. maidis in the environment, reducing the need of chemical control.

Key words: Insecta, Zea mays, pest management, corn leaf aphid, ecology.

O Brasil é um país de dimensões continentais e possui uma agricultura intensiva em boa parte de seu território. Os artrópodes-praga constituem em fatores limitantes à exploração racional e sustentável de várias culturas. Prejuízos diretos e/ou indiretos causados por esses organismos colocam o Brasil no grupo dos maiores usuários de produtos fitossanitários (Robbs \& Bittencourt, 1998). A semeadura extemporânea do milho, por favorecer a sucessão hospedeira das pragas, o que aliada ao uso intensivo de produtos fitossanitários tem sido responsável por desequilíbrios ecológicos nos agroecossistemas (Gassen \& Gassen, 1996). De acordo com Cruz (2004), nos últimos anos, insetos vetores de doenças como a cigarrinha-do-milho, Dalbulus maidis (DeLong \& Wolcott, 1923) (Hemiptera: Cicadellidae) e o pulgão Rhopalosiphum maidis (Fitch, 1856) (Hemiptera: Aphididae), têm ocor- rido com maior frequiência nesse tipo de cultivo.

Os pulgões de um modo geral, incluindo a espécie $R$. maidis são conhecidos pela capacidade de transmitir muitas viroses de plantas (Peña-Martínez, 1992; Smyrnioudis et al., 2000). A capacidade migratória desses insetos, é, portanto, crucial na disseminação dessas doenças. Para as viroses não transmissíveis pela semente, o estabelecimento inicial da infecção geralmente é resultado da chegada na planta hospedeira de formas aladas da praga contendo o vírus, ou de plantas infestadas remanescentes do cultivo anterior (Dewar et al., 1980). A disseminação subsequente do vírus dentro da área de cultivo é na maioria das vezes, o resultado do movimento entre plantas das formas ápteras dos pulgões. A extensão dessa disseminação secundária é influenciada tanto pelas condições ambientais (Holmes, 1988; Zuniga, 1990) como por fatores 
bióticos como estresse da planta (Bailey et al., 1995), seu estágio de crescimento (Jepson, 1983), estagio de desenvolvimento e densidade populacional do pulgão (Ito, 1960; Bakker \& Robinson, 1975; Hodgson, 1991) e ocorrência de inimigos naturais (Montgomery \& Nault, 1977; Roitberg et al., 1979; Zuniga, 1990).

Segundo Cruz (2004) a infestação desse afídeo inicia-se em plantas isoladas, disseminando-se em manchas na lavoura, com sua presença sendo constatada no período vegetativo e, principalmente, próximo ao lançamento do pendão. Nessa fase, as folhas encontram-se enroladas, formando cartucho de proteção, onde os pulgões sugam a seiva continuamente e multiplicam-se com facilidade, mas sem importância econômica direta. Todavia, altas infestações de pulgões, no período de pré-florescimento, podem ocasionar perda econômica, sendo fator crítico o estresse hídrico. Considera-se como fases críticas do desenvolvimento do milho os períodos de desenvolvimento da inflorescência, fertilização e enchimento de grãos (Everly, 1960; Brodbeck \& Strong, 1987; Honek 1990, 1991; Magalhães et al., 1995). O pulgão R. maidis no Brasil, era considerado como praga secundária na cultura mas, com o incremento do cultivo do milho "safrinha" na última década, tem sido verificado um aumento na sua população nessa cultura e em outras de importância econômica como a cana-de-açúcar, conforme salientado por Waquil et al. (1996).

Os efeitos da maior ou menor disponibilidade de umidade para as plantas são bem conhecidos (Hsiao, 1973). No entanto, os efeitos indiretos sobre os insetos fitófagos são bem menos conhecidos ou entendidos. Por exemplo, o desempenho de pulgões pode ser favoravelmente afetado (Wearing, 1967, 1972; Miles et al., 1982), pode ser prejudicado (Kennedy et al., 1958) ou ser indiferente (Pons \& Tatchell, 1995;
Bethke et al., 1998). A idade da planta e ou da folha (Ibbotson \& Kennedy, 1950; Kennedy et al., 1950; Wearing, 1967, 1972), a espécie de inseto (Wearing \& van Emdem, 1967; Oswaldo II \& Brewer, 1997) e o nível e a duração do estresse (Thomas \& Hodkinson, 1991; English-Loeb et al., 1997) podem também ser fatores determinantes sobre o impacto do estresse de umidade sobre os fitófagos. Mais especificamente, Hale et al. (2003), relataram que as taxas de ingestão de seiva do pulgão Rhopalosiphum padi foram significativamente reduzidas quando plantas de diferentes espécies de gramíneas estavam sob estresse de água.

A época do plantio, associada a fatores climáticos, poderá provocar alterações morfofisiológicas no milho e, conseqüentemente, na comunidade de artrópodes a ele associado como já demonstrado na literatura (Brodbeck \& Strong, 1987). O crescimento, a sobrevivência, a reprodução, o local de alimentação e a formação de pulgões alados, são grandemente influenciados pela concentração total de aminoácidos da dieta (Srivastava \& Auclair, 1971; Srivastava, 1987, e, plantas sob estresse hídrico ou com disponibilidade hídrica reduzida, tendem a uma maior concentração de aminoácidos (Dixon, 1987). Estes fatores, aliados ao incremento do cultivo do milho "safrinha" (Gassen, 1996), podem explicar as razões, pelas quais o pulgão $R$. maidis tem aumentado de importância. Assim, teve-se como objetivo avaliar aspectos biológicos do pulgão $R$. maidis nas fases de ninfa e de adulto, criados em milho, sob diferentes níveis de umidade do solo.

\section{Material e Métodos}

Os trabalhos foram iniciados em maio de 2002 em casa de vegetação do Departamento de Entomologia da UFLA, com o plantio de semen- 
tes de milho cultivar BRS 3133 cedidas pela Embrapa Milho e Sorgo, em doze vasos de dez litros, numerados e contendo uma mistura de terra e esterco na proporção 9:1. Os tratamentos foram aplicados cerca de 60 dias após o plantio (plantas de milho no estádio fenológico 3 ou com 12 folhas totalmente desenvolvidas) (Fancelli \& Dourado Neto, 2000).

Para se determinar a quantidade de água correspondente aos três níveis de água no solo $(20 \%, 40 \%$ e irrigado à capacidade de campo $=$ $100 \%$ de dotação d'água), duas semanas antes do início do experimento, com auxílio de uma proveta de $100 \mathrm{ml}$, irrigou-se todos os vasos anotando-se a quantidade de água necessária, a partir da qual cada vaso começou a vazar (capacidade de campo), variando de 700 a $1.200 \mathrm{ml}$. Dessa forma, determinou-se para cada vaso a quantidade de água necessária para o estabelecimento de cada tratamento. Por exemplo, para o estabelecimento de $20 \%$ da capacidade de campo, os vasos desse tratamento receberam $200 \mathrm{ml} / \mathrm{dia}=20 \%$ de $1000 \mathrm{ml}$.

O experimento foi conduzido em delineamento inteiramente casualizado (DIC) com três tratamentos (20, 40 e 100\% de dotação d'água) e

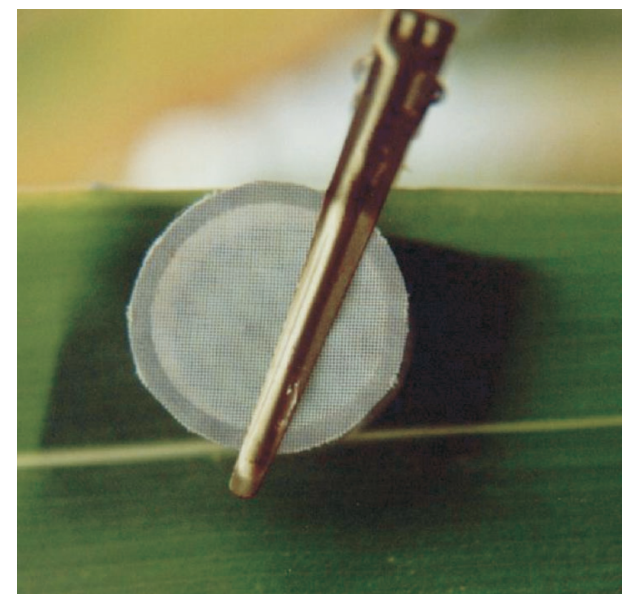

(A) quatro repetições, sendo cada parcela experimental constituída por um vaso com duas plantas e 10 pulgões adultos confinados em microgaiolas de $10 \mathrm{~mm}$ de altura por $10 \mathrm{~mm}$ de diâmetro (cinco pulgões/microgaiola/planta) (Figura 1), perfazendo um total de 40 pulgões/tratamento. No dia seguinte procedeu-se à verificação da presença de ninfas em cada gaiola e, em caso positivo, foi retirado o adulto, deixando-se apenas uma ninfa por gaiola. As características biológicas do pulgão, observadas no presente estudo, foram: a duração de cada ínstar e da fase ninfal; dos períodos pré-reprodutivo, reprodutivo e pós-reprodutivo; as produções diária de ninfas e de alados, e o ciclo de vida de $R$. maidis.

Para a determinação da temperatura e da umidade relativa do ar na casa de vegetação, foi mantido um termohigrógrafo próximo às unidades experimentais, em uma bancada protegida por um sombrite a 50\%, evitando, assim, a incidência direta dos raios solares. Os dados experimentais foram transformados para $\sqrt{(x+0,1)}$, antes de se proceder a análise de variância, que foi seguida do teste de agrupamento de médias de Scott e Knott $(P<0,05)($ Scott \& Knott, 1974).

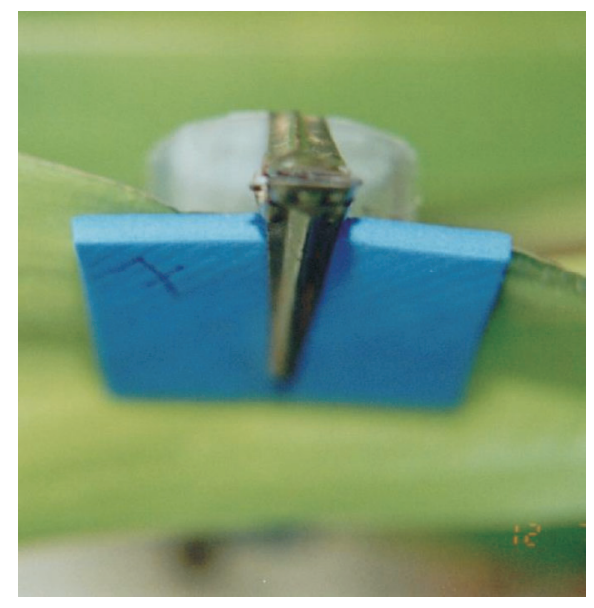

(B)

FIGURA 1 - Microgaiolas contendo uma ninfa recém nascida de Rhopalosiphum maidis em milho, cultivar BRS 3133, no estádio fenológico III. A: Vista superior; B: Vista inferior. UFLA, Lavras, MG, 2003. 


\section{Resultados e Discussão}

Foi verificado efeito dos níveis de dotação de água às plantas de milho, tanto na duração do desenvolvimento das ninfas em cada um dos quatro ínstares, quanto na duração da fase ninfal. Os pulgões cujos estádios de ninfa I, II,
III e IV ocorreram nas plantas que receberam $25 \%$ da água necessária para atingir a capacidade de campo, completaram esses estádios num menor período de tempo que os dos outros tratamentos, demonstrando que o estresse hídrico a $25 \%$ da capacidade de campo pode acelerar a velocidade de desenvolvimento das ninfas (Tabela 1).

TABELA 1. Duração média (dias) de cada instar e da fase ninfal de Rhopalosiphum maidis, em função de níveis de dotação hídrica.

\begin{tabular}{lccccc}
\hline & \multicolumn{5}{c}{ Estádios $^{1}$} \\
\cline { 2 - 6 } Tratamentos & Ninfa I & Ninfa II & Ninfa III & Ninfa IV & Fase ninfal total \\
\hline $20 \%$ da CC & $2,4 \mathrm{C}$ & $1,5 \mathrm{C}$ & $1,4 \mathrm{C}$ & $2,3 \mathrm{~B}$ & $7,6 \mathrm{C}$ \\
$40 \%$ da CC & $2,7 \mathrm{~B}$ & $2,2 \mathrm{~B}$ & $1,8 \mathrm{~B}$ & $2,6 \mathrm{~A}$ & $9,2 \mathrm{~B}$ \\
$100 \%$ da CC & $3,2 \mathrm{~A}$ & $2,6 \mathrm{~A}$ & $2,2 \mathrm{~A}$ & $2,8 \mathrm{~A}$ & $10,7 \mathrm{~A}$ \\
\hline CV $(\%)$ & 9,49 & 12,06 & 13,73 & 9,31 & 4,9 \\
\hline
\end{tabular}

${ }^{1}$ Médias seguidas pela mesma letra nas colunas, não diferem entre si pelo teste de $\mathrm{Scott} \& \operatorname{Knott}(\mathrm{P}<0,05)$. ${ }^{2} \mathrm{CC}=$ Capacidade de Campo.

Oswald II \& Brewer (1997), atestam que $R$. maidis criado em cevada, sob estresse hídrico, apresenta maior incremento na densidade populacional do que em plantas sem estresse hídrico. O comportamento de alimentação (penetração do estilete e sítios de alimentação) de $R$. maidis é afetado, tanto pelo estádio de desenvolvimento da planta do milho quanto pelo estresse hídrico da planta (Bing et al., 1991ab). Assim, a preferência pela colonização de plantas sob estresse hídrico, levando a perdas superiores a $90 \%$ na produção tem sido um dos fatores que interfere na relação trófica desse inseto-praga com os seus hospedeiros (Everly, 1960; Foott \& Timmins, 1973).

Durante o estádio fenológico 4 do milho, ocorrem modificações morfofisiológicas (Brodbeck \& Strong, 1987) que influenciam di- retamente o comportamento alimentar de $R$. maidis. $\mathrm{O}$ aumento na produção e transporte de fotoassimilados e a concentração de nutrientes para a formação dos grãos de pólen (Fancelli \& Dourado Neto, 2000), exercem influência sobre a densidade da colônia. Segundo Fancelli \& Dourado Neto (2000), o maior fluxo de nutrientes das raízes para a região do pendão das plantas de milho, pode provocar uma maior atração do pulgão. $\mathrm{O}$ valor da proteína ingerida pelo inseto depende do conteúdo de aminoácidos e da capacidade do inseto em digerir essa proteína (Parra, 1994). Portanto, é provável que a maior concentração de aminoácidos na seiva das plantas de milho sob estresse hídrico melhore o suprimento alimentar do pulgão.

Honek (1990, 1991), observou a influência dos estádios fenológicos do trigo, sobre po- 
pulações de $R$. maidis e postulou que o aumento da concentração e disponibilidade de aminoácidos livres constituem no maior ou no único componente alimentar para os insetos sugadores especializados como os afídeos (Parra, 1999) fenômeno que é determinado pelo estádio fenológico e pela disponibilidade de solutos na planta (Leather \& Dixon, 1980; Brodbeck \& Strong, 1987).

Houve efeito dos níveis de dotação de água às plantas do milho, nas características biológicas do pulgão na fase adulta. O período reprodutivo e a longevidade de $R$. maidis foram mais curtos em pulgões que se desenvolveram em plantas de milho em solo com $20 \%$ da capacidade de campo, porém não houve efeito dos tratamentos na duração do período pósreprodutivo (Tabela 2). Por outro lado, adultos do pulgão que se desenvolveram nessas mesmas plantas colocaram a primeira ninfa num menor período de tempo em relação aos que se desenvolveram em plantas de milho em solo com $40 \%$ da capacidade de campo. Estes por sua vez colocaram a primeira ninfa num menor período de tempo que os das plantas que receberam água na capacidade de campo (100\% de dotação d'água) (Tabela 2).

TABELA 2. Duração dos períodos e da longevidade (dias) de Rhopalosiphum maidis, em função da umidade do solo.

\begin{tabular}{|c|c|c|c|c|}
\hline \multirow[b]{2}{*}{ Tratamentos } & \multicolumn{3}{|c|}{ Períodos/duração ${ }^{1}$} & \multirow[b]{2}{*}{ Longevidade } \\
\hline & Pré-reprodutivo & Reprodutivo & Pós-reprodutivo & \\
\hline $20 \%$ da $\mathrm{CC}^{2}$ & $0,6 \mathrm{C}$ & $11,0 \mathrm{C}$ & $2,7 \mathrm{~A}$ & $14,3 \mathrm{C}$ \\
\hline $40 \%$ da CC & $1,3 \mathrm{~B}$ & $12,8 \mathrm{~B}$ & $2,8 \mathrm{~A}$ & $17,0 \mathrm{~B}$ \\
\hline $100 \%$ da CC & $3,2 \mathrm{~A}$ & $14,3 \mathrm{~A}$ & $3,1 \mathrm{~A}$ & $20,5 \mathrm{~A}$ \\
\hline CV $(\%)$ & 28,48 & 5,52 & 14,24 & 5,09 \\
\hline
\end{tabular}

${ }^{1}$ Médias seguidas pela mesma letra nas colunas, não diferem entre si pelo teste de $\mathrm{Scott} \& \operatorname{Knott}(\mathrm{P}<0,05)$. ${ }^{2} \mathrm{CC}=$ Capacidade de Campo.

Observou-se que o suprimento de $20 \%$ da capacidade de campo foi mais severo sobre o ciclo biológico total de $R$. maidis que o de $40 \%$ da capacidade de campo e este, por sua vez, mais que o de dotação total da água. As ninfas que se alimentaram de plantas de milho sob estresse hídrico de $80 \%$ (receberam apenas $20 \%$ da água necessária) desapareceram mais rapidamente do ambiente que aquelas desenvolvidas em plantas com $60 \%$ e sem estresse (Tabela 3 ). Esses resultados demonstram que o manejo da água no cultivo do milho pode ser uma ferramenta impor- tante para a regulação, tanto da fertilidade como do número de gerações desse pulgão nos agroecossistemas, reduzindo a necessidade do uso de produtos fitossanitários para o seu controle.

As variáveis, número ninfas/dia e total de pulgões alados mostraram que o estresse hídrico aumenta a produção de ninfas e, consequentemente, acelera a necessidade de abandono da colônia, produzindo mais pulgões alados. Embora não se altere o número total de ninfas produzidas em função das mudanças no suprimento de água, ausência da qual propulsiona o estresse 
da planta, tornando-a vulnerável ou mais resistente ao ataque de pragas e doenças, fato que é determinado pelo espessamento da parede celu- lar ou pelo baixo poder da planta em mobilizar nutrientes que seriam alocados para a construção do arcabouço e massa do inseto-praga.

TABELA 3. Duração (dias) do ciclo biológico e produção diária e total de ninfas de Rhopalosiphum maidis, em função da umidade do solo.

\begin{tabular}{lcccc}
\hline \multirow{2}{*}{ Tratamentos } & \multirow{2}{*}{ Ciclo biológico } & \multicolumn{3}{c}{ Produção de insetos } \\
\cline { 3 - 5 } & & Total de ninfas & Ninfas/dia & Total de alados \\
\hline \multirow{2}{*}{$20 \%$ da CC } & $21,9 \mathrm{C}$ & $23,6 \mathrm{~A}$ & $2,2 \mathrm{~A}$ & $12,4 \mathrm{~A}$ \\
$40 \%$ da CC & $26,2 \mathrm{~B}$ & $21,7 \mathrm{~A}$ & $1,7 \mathrm{~B}$ & $5,8 \mathrm{~B}$ \\
$100 \%$ da CC & $31,3 \mathrm{~A}$ & $19,8 \mathrm{~A}$ & $1,4 \mathrm{C}$ & $6,1 \mathrm{~B}$ \\
\hline $\mathrm{CV}(\%)$ & 3,73 & 14,18 & 12,61 & 15,20 \\
\hline
\end{tabular}

${ }^{1}$ Médias seguidas pela mesma letra na coluna, não diferem entre si pelo teste de $\operatorname{Scott} \&$ Knott $(\mathrm{P}<0,05)$ ${ }^{2} \mathrm{CC}=$ Capacidade de Campo.

Em geral, todos os estádios de desenvolvimento de $R$. maidis em plantas de milho submetidas a diferentes suprimentos de água, demonstraram ser altamente influenciados pelos diferentes tratamentos. O défice hídrico de $80 \%$ da capacidade de campo, também promoveu o rápido amadurecimento e definhamento das plantas de milho, situação que pode justificar o efeito sobre os estádios do inseto como a longevidade, o ciclo biológico, a produção de ninfas e a emigração dos adultos demonstrada pelo alto número de insetos alados (Tabela 3). Wiktelius (1992), postulou que $R$. padi criado em cevada em dois estádios fenológicos, amadurecimento da planta e lançamento da espiga, acelerou a produção de ninfas aladas de quarto ínstar, independentemente da sua densidade populacional.

Como a duração do período reprodutivo relacionou-se inversamente com a fecundidade de $R$. maidis, o tratamento com $20 \%$ de suprimento de água exerceu maior influência, produ- zindo acima de 22 e $36 \%$ de ninfas/dia, quando comparado com os tratamentos $40 \%$ e $100 \%$, respectivamente. Embora não tenha sido constatado efeito significativo desses tratamentos na produção total de ninfas (Tabela 3).

Não houve efeito dos diferentes tratamentos na produção total de ninfas, demonstrando que em plantas sob estresse hídrico o aumento da população do inseto se dá pela redução do ciclo, aumentando o número de gerações em 1,43 vezes (Tabela 3). Entretanto, em $R$. padi, de acordo com Pons \& Tatchell (1995), a taxa reprodutiva em trigo de inverno sob estresse hídrico (temperatura média de $14{ }^{\circ} \mathrm{C}$ ), foi menor. Além de se tratar de outra espécie de pulgão e cultura, as condições ambientais e metodológicas de criação do pulgão foram diferentes o que pode ter afetado os resultados (Foott \& Timmins, 1973; Bing et al., 1991a,b).

Em estudos sobre a fisiologia de plantas de milho, tem sido levantada a hipótese de que a 
manutenção da pressão de turgescência celular através do acúmulo de solutos seja um mecanismo de adaptação da planta para seu crescimento ou sobrevivência em períodos de estresse hídrico. Essa falta de água é sempre acompanhada por interferência nos processos de síntese de RNA e proteína, caracterizada por um aumento aparente na quantidade de aminoácidos livres, como a prolina, que tem sido sugerida como fonte de energia para a atividade circadiana dos insetos (Magalhães et al. 1995). Níveis de amido são freqüentemente maiores em plantas após o estresse hídrico, e parece que o amido é um veículo comum no transporte de nitrogênio (Brodbeck \& Strong, 1987).

Aparentemente, surtos de insetos herbívoros, estão associados ao estresse hídrico em plantas hospedeiras que incrementam a concentração de certos aminoácidos cruciais para a fecundidade ou sobrevivência dos insetos. Por outro lado, mudanças nas condições do ambiente determinam as concentrações de aminoácidos específicos em plantas, os quais podem correlacionar-se com o sucesso da fitofagia ou abundância. Um exemplo típico é o que ocorre em plantas desenvolvidas sob solos ácidos e que absorvem o nitrogênio na forma de nitrato e, outro àquelas sob solos com $\mathrm{pH}$ mais elevado que tendem a absorver mais íons de amônio, fato que deve determinar a rota metabólica e os subprodutos (Fancelli \& Dourado Neto, 2000). De certa forma, o estresse em plantas pode também causar um declínio na síntese de proteínas e um incremento na produção de aminoácidos livres, fonte de nutrição de insetos sugadores. Assim os principais responsáveis pelas mudanças em função do estresse hídrico podem ser indicados como a concentração e composição de aminoácidos livres e em forma de proteínas, os quais mudam com o estresse (Brodbeck \& Strong, 1987).
De acordo com Honek (1991), diferenças no metabolismo de plantas de trigo afetaram a performance de $R$. maidis, o qual preferiu se alimentar nos órgãos das plantas com maior proporção de matéria seca. Aparentemente, dentre os fatores que afetaram a performance dos insetos destacaram a produção, o transporte de assimilados e a morfologia dos órgãos das plantas.

Portanto, pode-se concluir que o pulgãodo-milho, $R$. maidis, responde ao estresse hídrico no milho reduzindo o seu ciclo biológico e, consequentemente seu potencial biótico, além de aumentar a produção de formas aladas, que são as responsáveis tanto pela migração quanto pela dispersão da espécie no campo.

\section{Literatura Citada}

BAILEY, S. M.; IRWIN, M. E.; KAMPMEIER, G. E.; EASTMAN, C. E.; HEWINGS, A. D. Physical and biological perturbation of apterous Rhopalosiphum padi (Homoptera: Aphididae) and localized spread of barley yellow dwarf virus. Environmental Entomology, College Park, v. 24, p. 24-33, 1995.

BAKKER, T.; ROBINSON, A. C. Movement of english grain aphids on barley plants. Manitoba Entomologist, Winnipeg, v. 9, p. 9-12, 1975.

BETHKE, J. A.; REDAK, R. A.; SCHUCH, U. K. Melon aphid performance on chrysanthemum as mediated by cultivar and differential levels of fertilization and irrigation. Entomologia Experimentalis et Applicata, Dordricht, v. 88, p. 41-47, 1998.

BING, J. W.; GUTHRIE, W. D.; DICKE, F. F.; OBRYCKI, J. J. Seedling stage feeding by corn leaf aphid (Homoptera: Aphididae): influence on plant development in maize. Journal of Economic Entomology, Lanham, v. 84, n. 2, p. 625-632, 1991a. 
BING, J. W.; NOVAK, M. G.; OBRYCKI, J. J.; GUTHRIE, W. D. Stylet penetration and feeding sites of Rhopalosiphum maidis (Homoptera: Aphididae) on two growth stages of maize. Annals of the Entomological Society of America, Lanham, v. 84, n. 5, p. 549-554, 1991 b.

BRODBECK, B.; STRONG, D. Amino acid nutrition of herbivorous insects and stress to host plants. In: BARBOSA, P.; SCHULTZ, J. C. (Ed.)., Insect Outbreaks. San Diego: Academic Press, 1987. Cap. 14 , p. $347-364$

CRUZ, I. Manejo de pragas da cultura do milho. In: GALVÃO, J. C. C. \& MIRANDO, G. V. (Eds.) Tecnologias de produção de milho, UFV: Viçosa, 2004. cap. 9, p. 311-366.

DEWAR, A. M.; WOIWOD, I.; CHOPPIN DE JANVRY, E. Aerial migration of the rose-grain aphid Metopolophium dirhodum (Wlk), over Europe in 1979. Plant Pathology, London, v. 29, p. 101-109, 1980.

DIXON, A. F .G. The way of life of aphids: host specificity, speciation and distribution. In: MINKS, A. K.; HARREWINJN, P. (Ed.) World crop pests: their biology, natural enemies and control. Amsterdam: Elsevier, 1987. Cap. 41, p. 197-207.

ENGLISH-LOEB, G. M.; STOUT, M. J.; DULFEY, S. S. Drought stress in tomatoes: changes in plant chemistry and potential nonlinear consequences for insect herbivores. Oikos, Buenos Aires, v. 79, p. 456-468, 1997.

EVERLY, R. T. Loss in corn yield associated with the abundance of the corn leaf aphid, Rhopalosiphum maidis, in Indiana. Journal of Economic Entomology, Lanham, v. 53, n. 5, p. 924-932, 1960.
FANCELLI, A. L.; DOURADO NETO, D. Produção de milho, Guaíba: Agropecuária, 2000. 360 p.

FOOTT, W. R.; TIMMINS, P. R. Effects of infestations by the corn leaf aphid, Rhopalosiphum maidis (Homoptera: Aphididae), on field corn in southwestern Ontario. Canadian Entomologist, Ottawa, v. 105, p. 49-458, 1973.

GASSEN, D. N. Manejo de pragas associadas à cultura do milho. Passo Fundo:Aldeia Norte, 134 p. 1996.

GASSEN, D.N.; GASSEN, F.R. Plantio direto, o caminho do futuro, Passo Fundo:Aldeia Norte, 207 p. 1996.

HALE, B. K.; BALE, J. S.; PRITCHARD, J.; MASTERS, G. J.; BROWN, V. K. Effects of host plant drought stress on the performance of the bird cherry-oat aphid, Rhopalosiphum padi (L.): a mechanism analysis. Ecological Entomology, Oxford, v. 28, p. 666-677, 2003.

HODGSON, C. Dispersal of apterous aphids (Homoptera: Aphididae) from their host plant and its significance. Bulletin of Entomological Research, London, v. 81, p. 417-427, 1991.

HOLMES, P. R. Mobility of the apterous grain aphids, $S$. avenae within wheat fields. Entomologia Experimentalis et Applicata, Dordrecht, v. 46, p. 275-279, 1988.

HONEK, A. Host plant energy allocation to and within ears, and abundance of cereal aphids. Journal of Applied Entomology, Hamburg, v. 110, p. 68-72, 1990.

HONEK, A. Environment stress, plant quality and abundance of cereal aphids (Hom., Aphididae) on winter wheat. Journal of Applied Entomology, Hamburg, v.112, p. 65-70, 1991. 
HSIAO, T. C. Plant responses to water stress. Annual Review of Plant Physiology, Palo Alto v. 24, p. 519-570, 1973.

IBBOTSON, A.; KENNEDY, J. S. The distribution of aphid infestation in relation to leaf age II: the progress of Aphis fabae Scop. infestations on sugar beet in pots. Annals of Applied Biology, Cambridge, v. 37, p. 680-696, 1950.

ITO, Y. Ecological studies on population increase and habitat segregation among barley aphids. Bulletin of National Institution of Agriculture Science. v. 11, p. 45-127, 1960.

JEPSON, P. C. A controlled environment study of the effect of leaf physiological age on movement of apterous Myzus persicae on sugarbeet plants. Annals of Applied Biology, Cambridge, v. 103, p. 173-183, 1983.

KENNEDY, J. S.; IBBOTSON, A.; BOOTH, O. The distribution of aphid infestation in relation to leaf age I: Myzus persicae (Sulz.) and Aphis fabae Scop. on spindle trees and sugar-beet plants. Annals of Applied Biology, Cambridge, v. 37, p. 651-679, 1950.

KENNEDY, J. S.; LAMB, K. P.; BOOTH, C. O. Responses of Aphis fabae Scop. to water shortage in host plants in pots. Entomologia Experimentalis et Applicata, Dordrecht, v. 1, p. 274-291, 1958.

LEATHER, S. R.; DIXON, A. F. G. The effect of cereal growth stage and feeding site on the reproductive activity of the bird-cherry aphid, Rhopalosiphum padi. Journal of Applied Entomology, Hamburg, v. 97, p. 135-140. 1980 MAGALHÃES, P. C.; DURÃES, F. O. M.; PAIVA, E. Fisiologia da planta de milho, Sete
Lagoas: EMBRAPA-CNPMS, 1995. 27 p. (EMBRAPA-CNPMS. Circular Técnica, 20).

MILES. P. W.; ASPINALL, D.; ROSENBERG, L. Performance of the cabbage aphid, Brevicoryne brassicae (L.), on water-stressed rape plants, in relation to changes in their chemical composition. Australian Journal of Zoology, Victoria, v. 30, p. 337-345, 1982.

MONTGOMERY, M. E.; NAULT, L. R. Aphid alarm pheromone: dispersion of Hyadaphis erysini and Mysus persicae. Annals of the Entomological Society of America, College Park, v. 70, p. 669-672, 1977.

OSWALD II, C. J.; BREWER, M. J. Aphid-barley interactions mediated by water stress and barley resistance to Russian wheat aphid (Homoptera: Aphididae). Environmental Entomology, Lanham, v. 26, n. 3, p. 591-602, 1997.

PARRA, J. R. P. Técnicas de criação de insetos para programas de controle biológico. 2. ed. Piracicaba: ESALQ/FEALQ, 1994. $196 \mathrm{p}$.

PARRA, J. R. P. Técnicas de criação de insetos para programas de controle biológico. Piracicaba: ESALQ/FEALQ, 1999. 137 p.

PEÑA-MARTINEZ, M. R. Biologia de áfidos y su relación con la transmisión de virus. In: URIAS-M., C.; RODRÍGUEZ-M., ALEJANDRE-A., T. (Eds.) Afidos como vectores de virus en México. México: Centro de Fitopatologia, Montecillo, 1992. v. 1.p. 11-35

PONS, X.; TATCHELL, G. M. Drought stress and cereal aphid performance. Annals of Applied Biology, Cambridge, v.22, p.19-31. 1995. 
ROBBS, C. F.; BITTENCOURT, A. M. Controle biológico de insetos. Revista Biotecnologia, v. 2, n. 6, p. 10-12, 1998.

ROITBERG, B. D.; MYERS, J. H.; FRAZER, B. D. The influence of predators on the movement of apterous pea aphids between plants. Journal of Animal Ecology, Oxford, v. 48, p. 111-122, 1979.

SCOTT, A. J.; KNOTT, M. A. A cluster analyses method for grouping means in the analyses of variance. Biometrics, Raleigh, v. 30, n. 3, p. 502512, 1974.

SMYRNIOUDIS, I. N.; HARRINGTON, R.; KATIS, N.; CLARK, S. J. The effect of drought stress and temperature on spread of barley yellow dwarf virus (BYDV). Agricultural and Forest Entomology, v. 2, p. 161-166, 2000.

SRIVASTAVA, P. N. Nutritional physiology. In: MINK, A. K.; HARREWIJN, P. (Eds.). Aphids: their biology, natural enemies and control. Amsterdan, Elsevier: 1987. p. 99-121.

SRIVASTAVA, P. N.; AUCLAIR, J. L. Influence of sucrose concentration on diet uptake and performance by the pea aphid, Acyrthosiphom pisum. Annals of the Entomological Society of America, College Park, v. 64, p. 739-743, 1971.

THOMAS, A. T.; HODKINSON, I.D. Nitrogen, water stress, and the feeding efficiency of lepidopteran herbivores. Journal of Applied Ecology, Oxford, v. 28, p. 703-720, 1991.
WAQUIL, J. M.; OLIVEIRA, E.; PINTO, N. F .J .A.; FERNANDES, F. T.; CORREA, L. A. Efeito na produção e incidência de viroses em híbridos comerciais de milho. Fitopatologia Brasileira, Brasília, DF, v. 21, n. 4, p. 460-63, 1996.

WEARING, C. H.; VAN EMDEN, H. F. Studies on the relations of insect and host plant. I. Effects of water stress in host plants on infestation by Myzus persicae (Sulz.) and Brevicoryne brassicae (L.). Nature, London, v. 203, p.1051-1052, 1967.

WEARING, C. H. Studies on the relations of insect and host plant. II. Effects of water stress on host plant on the fecundity of Myzus persicae (Sulz.) and Brevicoryne brassicae (L.). Nature, London, v. 203, p. 1052-1053, 1967.

WEARING, C.H. Responses of Myzus persicae and Brevicoryne brassicae to leaf age and water stress in Brussels sprouts grown in pots. Entomologia Experimentalis et Applicata, Dordrecht, v. 15, p. 61-80, 1972.

WIKTELIUS, S. The induction of alate in Rhopalosiphum padi (L.) (Hom., Aphididae) in relation to crowding and plant growth stage in spring sown barley. Journal of Applied Entomology, Hamburg, v. 114, p. 491-496. 1992.

ZUNIGA, E. Effect of parasitism and rainfall on displacement movements of aphids. In: PETERS, D.C.; WEBSTER, J. A.; CHLOUBER, C. S. (Eds.). Aphid-Plant interactions: Populations to Molecules. USDA - Agricultural Research Service: Oklahoma State University, 1990. 